\title{
Medicinal Plants:-Traditional Knowledge and Practices in Some Communities of Ethiopia
}

\author{
Zeleke Wolde Tenssay, Edigetu Merawi, Tesfaye Bekele, Binyam Goshu, Yibrahu Emishaw, \\ Ashenafi Ayehune
}

Access and Benefit Sharing Directorate, Ethiopian Biodiversity Institute, Addis Ababa, Ethiopia

\section{Email address:}

otense2002@yahoo.co.uk (Z.W.Tenssay), edegetmerawi@gmail.com (E. Merawi), tesfayebekele97@yahoo.com (T. Bekele), biniamgoshu40@gmail.com (B. Goshu),yibrehu27@gmail.com (Y. Emishaw), ashenafiayenew@ibc.gov.et (A. Ayehune)

\section{To cite this article:}

Zeleke Wolde Tenssay, Edigetu Merawi, Tesfaye Bekele, Binyam Goshu,Yibrahu Emishaw, Ashenafi Ayehune. Medicinal Plants:-Traditional Knowledge and Practices in Some Communities of Ethiopia. International Journal of Ecotoxicology and Ecobiology.

Vol. 2, No. 2, 2017, pp. 56-60. doi: 10.11648/j.ijee.20170202.11

Received: June 22, 2016; Accepted: May 17, 2017; Published: June 30, 2017

\begin{abstract}
In Ethiopia, traditional knowledge associated with medicinal plants are being seriously depleted due to deforestation, environmental degradation and acculturation that have been taking place. The present study documented traditional knowledge associated with medicinal plants in Decha (Keffa) and Sheybench (BenchMaji) districts of Southern Nations, Nationalities and. The objective of the study was to identify and record traditional knowledge and practices associated with the medicinal plants with special emphasis on plants with potential for bio-prospecting. The study method was interviewing selected herbal practitioners and elderly people by means of a semi-structured questionnaire and focus group discussion. Out of 146 species of medicinal plants collected from the study area, herbs (41.4\%) and shrubs (35.5\%) constituted the highest proportion, followed by trees $(16.2 \%)$ and climbers $(6.9 \%)$. Out of the total of 146 medicinal plants collected 95(64.7\%) were used against human disease, 32(21.9\%) of medicinal plants were used against animal disease and the remaining $18 \%$ were used for the treatment of both human and animal diseases. The results showed relatively a higher proportions of plant species were found to be used for the treatments of respiratory diseases $(32.8 \%)$, followed by for the treatment of miscellaneous disease conditions such as swellings/tumors, toothache, headache, etc. (20.9\%), and gastrointestinal related complaints (18.4\%). The most frequent methods $(95.7 \%)$ of preparation of plant medicines in the studied communities were squashing/grinding of plant parts and extracting juicy ingredients. Although there is wealth of medicinal plants and traditional knowledge that has been applied in the treatment of human and lifestalk health problems, the sustainability of these heritages has been challenged increasingly by human and environmental factors. According to some respondents the traditional medicinal practices has been discouraged by modern health care system due to fear of inappropriate dosage and safety issue. Therefore in addition to documenting traditional medicinal plants and the associated knowledge, it is important to test the scientific validity of the herbal preparations to establish appropriate dosages and conduct clinical studies to ensure the safety of the traditional medicines if we are to benefit sustainably from these heritages.
\end{abstract}

Keywords: Traditional Knowledge, Medicinal Plants, Traditional Medicine, Associated Knowledge, Respondents, Herbal Practitioners

\section{Introduction}

Traditional knowledge is vital for sustainability of natural resources including forests, water, and agro-ecosystems across landscape continuum spanning from households through farms, village, commons and wilderness [1]. Humanity faces exceptional challenge of eroding natural resources and declining ecosystems services due to a multitude of threats created by unprecedented growth and misappropriation. Misappropriation of genetic resources and traditional knowledge through intellectual property claims has effected in loss of biological resources of countries rich in the biological diversity $[1,2]$. The patent claims have been made without evidence of the prior informed consent of the 
people from whom these resources and knowledge were taken, and without the existence of mutual agreement on sharing the benefits from use of the resources [1, 2, and 3].

The Convention on biological Diversity (CBD) recognized the close and traditional dependence of indigenous and local communities on biological resources and the need to ensure that these communities share the benefits arising from the use of their traditional knowledge and practices relating to the conservation and sustainable use of biodiversity [3, 4]. Member governments have agreed to respect, preserve and maintain such knowledge and practices, to promote their wider application with the approval and involvement of the communities concerned, and to encourage the equitable sharing of the benefits derived from their utilization $[4,5,6]$. The Nagoya protocol on access to genetic resources and fair and equitable sharing of benefit from the use of genetic resources is a recently developed international legal frame work that has given legal status to genetic resources and associated traditional knowledge [7, 8].

In Ethiopia, traditional knowledge associated with medicinal plants are being seriously depleted due to deforestation, environmental degradation and acculturation that have been taking place in the country for quite a long time $[10,11,12,13]$. This could ultimately result in the weakening of primary health care services in the country, as most of the people are highly dependent on plant based traditional medical practices $[11,12,13]$. As more and more medicinal plants and the associated knowledge are lost, the potential for the future development of modern herbal drugs could also be compromised. Thus studies are needed to salvage the medicinal plants and the associated knowledge from further loss.

Therefore the present study aims at documenting traditional knowledge associated with medicinal plants in some zones and districts of Southern Nations, Nationalities and Peoples Regions.

The objective of the study was to identify and record traditional knowledge and practices associated with the medicinal plants with special emphasis on plants with potential for bio-prospecting.

\section{Materials and Methods}

\subsection{Study Areas}

Two districts (Woreda) (Decha and SheyBench) with diverse plants species and community knowledge and practices were selected from Southern Nations Nationalities and Peoples Region (SNNPRs) with the help Zonal administrative and Agricultural offices of the region. The Districts are located at about $528 \mathrm{~km}$ and $650 \mathrm{~km}$ from Addis Ababa respectively. According to 2007 census, the total population of Decha district was 128,853 , whereas that of SheyBench was 208,339. The annual rain fall of Decha ranges from 1165-2200 mm with altitudes of 500-3200 above sea level, whereas SheyBench district receives an annual rain fall ranging from $2111 \mathrm{~mm}-2565 \mathrm{~mm}$ [11]. Although the proportion differs, there are three agro-ecological zones, Dega (Cool), Woina dega (medium) and Kola(hot) in both of the studied districts.

\subsection{Methods of Data Collection}

Ethnobotanical data were collected from Decha and SheyBench districts from March up to April 2016. The study was conducted by interviewing selected herbal practitioners and elderly people from 3 urban and 3 rural Kebels (lowest administrative structures) from each district by means of a semi-structured questionnaire and focus group discussion. The interview was conducted by local languages (Bench and Kaffa) with the help of translators. During the interview session each informant was asked to give information on the type of plants, parts of the plant used, ailments treated, route of administration, ways of remedy preparation, dosage, marketability of the plant, means of knowledge transfer and charge for the medication.

\subsection{Plant Specimens Collectionand Taxonomy}

Voucher specimens were collected from each of the sampled Kebele, labeled and transported to Ethiopian Biodiversity Institute (EBI) Herbarium, Addis Ababa. The specimens were identified using paired key following Flora of Ethiopia and comparing Voucher specimens displayed at the EBI Herbarium.

\subsection{Data Analysis}

Information from questionnaires was entered into SPSS 21 and descriptive statistical analysis was used to summarize the data.

\section{Results and Discussion}

\subsection{Socio-demographic}

A total of 116 respondents were involved in the study from the two different districts.Although the plan was to interview 21 respondents from each Keble, some informants were absent during the interview from Kuka and Kusha (SheyBench districts, BenchMaji) and one respondent was included in Uffa (Decha district, Kaffa) (Table1) because it was indicated by the facilitators of the Kebele that the same was known for his herbal practices. The gender of respondents was recorded during the interview and of the total 116 respondents, 102 were males and the remaining 14 were females (Table2). Although there was a prior notice to include a fair proportion of females in the study, the number of females involved in the study was by far lower than that of males ,this may be due to engagement of females in multiple activities both at home and on the farm.

Table 1. Kebles studied and number of respondents in the study.

\begin{tabular}{lllllll}
\hline \multicolumn{2}{l}{ Kebeles from Decha } & \multicolumn{4}{l}{ Kebeles from SheyBench } & Total \\
\hline Uffa & Beha & Kutti & Kasheta & Kuka & Kusha & \\
\hline 22 & 21 & 21 & 21 & 17 & 14 & 116 \\
\hline
\end{tabular}


Table 2. Gender of the respondents in study.

\begin{tabular}{llll}
\hline Distri ct of respondents & \multicolumn{3}{l}{ Sex of respondents } \\
\hline & Male & Female & Total \\
\hline SheyBench & 46 & 6 & 52 \\
Decha & 56 & 8 & 64 \\
Total & 102 & 14 & 116 \\
\hline
\end{tabular}

Table 3. Educational Levels of Respondents.

\begin{tabular}{llllll}
\hline District of & \multicolumn{5}{l}{ Educational Level } \\
\cline { 2 - 6 } respondents & illiterate & Primary & Secondary & Diploma & Total \\
\hline SheyBench & 25 & 26 & 1 & 0 & 52 \\
Decha & 22 & 30 & 9 & 3 & 64 \\
Total & 47 & 56 & 10 & 3 & 116 \\
\hline
\end{tabular}

The majority $56(48 \%)$ of respondents attended primary level of education, whereas, $47(41 \%)$ respondents cannot read and write (illiterates), only $10(9 \%)$ of the respondents have an educational level of secondary education and above (Table 3).

Similarly the ages of the study respondents is given in Table4. The majority of respondents both from Shey-Bench and Decha districts fall in the age group 31-45 years. Inspite of our expectation that the number of respondents in the age group46-60 would be more frequent in the traditional knowledge study of this kind, only 21 respondents of that age group were involved in the study. This may be due to factors such as the distance of the interview site from their homes.

Table 4. Age of respondents

\begin{tabular}{lllll}
\hline \multirow{2}{*}{ District of respondents } & \multicolumn{3}{l}{ Age of respondents } & \multirow{2}{*}{ Total } \\
\cline { 2 - 4 } & $\mathbf{1 8 - 3 0}$ & $\mathbf{3 1 - 4 5}$ & $\mathbf{4 6 - 6 0}$ & \\
\hline SheyBench & 14 & 28 & 10 & 52 \\
Decha & 17 & 35 & 12 & 64 \\
Total & 31 & 63 & 22 & 116 \\
\hline
\end{tabular}

\subsection{Floristic Diversity of Medicinal Plants}

A total of 146 medicinal plant species belonging to 57 families were recorded in the study area

The most frequently reported as medicinally used families in the community are given in Table 5 .

Table 5. Medicinal Plant families that have highest frequency of the study area.

\begin{tabular}{llll}
\hline S.No & Family & Frequency & Percentage \\
\hline 1 & Asteraceae & 86 & 14.4 \\
2 & Lamiaceae & 85 & 14.2 \\
3 & Ranunculaceae & 40 & 6.7 \\
4 & Euphorbiaceae & 35 & 5.9 \\
5 & Rutaceae & 32 & 5.4 \\
6 & Fabaceae & 25 & 4.2 \\
7 & Phytolaccaceae & 22 & 3.7 \\
8 & Boraginaceae & 16 & 2.7 \\
9 & Polygonaceae & 16 & 2.7 \\
10 & Myrsinaceae & 14 & 2.3 \\
11 & Solanaceae & 12 & 2 \\
12 & Poaceae & 10 & 1.7 \\
13 & Rosaceae & 10 & 1.7 \\
14 & Asparagaceae & 9 & 1.5 \\
15 & Dracaenaceae & 9 & 1.5 \\
16 & Urticaceae & 9 & 1.5 \\
17 & Amaranthaceae & 8 & 1.3 \\
18 & Apiaceae & 8 & 1.3 \\
19 & Vitaceae & 8 & 1.3 \\
\hline
\end{tabular}

Out of 146 species of medicinal plants collected from the study area, herbs $(41.4 \%)$ and shrubs $(35.5 \%)$ constituted the highest proportion, followed by trees $(16.2 \%)$ and climbers (6.9\%) (Fig2). Mirutse et al (11) documented a similar trend from Menit district in the same zone. Similarly, Maroyi(14) reported from Zimbabwe abundance of shrubs and herbs but he recorded greater number of shrubs.

\subsection{Parts of Plants Used for the Treatment of Different Ailments}

Informants of the study areas indicated that different parts of plants including leaves, roots, seeds, barks, fruits or combinations of these may be used for traditional treatment of diseases. According to the respondent's more species $(71.7 \%)$ were harvested to use their leaves, followed by roots $(11.4 \%)$ and whole plant $(6.9 \%)$ in medicine preparation (Fig1). Previous studies from Ethiopia and elsewhere in the world $(11,12$, and 14$)$ also showed similar findings.

From the total of 146 medicinal plants collected 95 $(64.7 \%)$ of medicinal plants were used against human disease, $32(21.9 \%)$ of medicinal plants were used against animal disease and the remaining $18 \%$ were used for the treatment of both human and animal diseases. This result is similar to the one reported by Reta Regassa (15) and Mirtuse et al (11) whose reports indicated that most of the medicinal plants collected were used against human diseases.

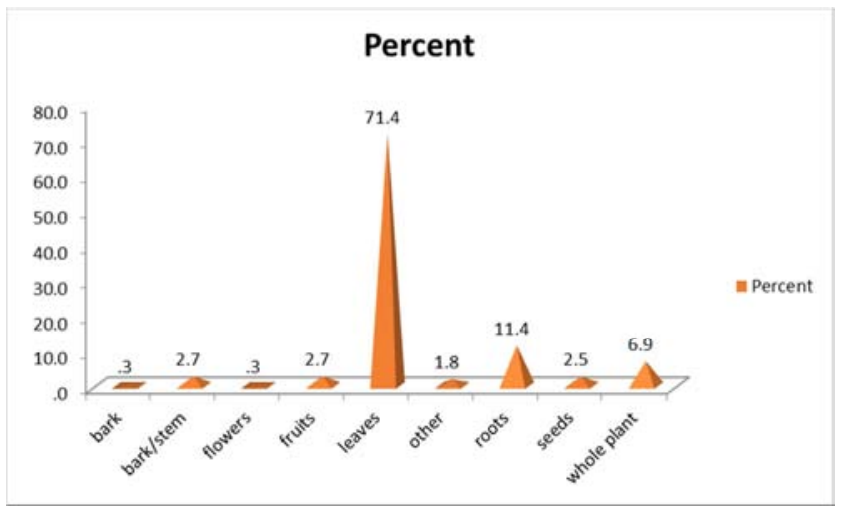

Figure 1. Plant parts used for tradition medicine by studied community.

\subsection{Type of Diseases Treated}

The major health problems/disease conditions/treated by traditional medicine in the study areas are depicted in figure 2. In general, they were categorized as gastrointestinal (oral, Abdominal and intestinal), respiratory (nasal, nasopharyngeal, trachea, lung etc.), urinary/uro-genital, rabid animal bite, eye infection, skin infection, snake poison, wound and others (Fig. 2). The results showed relatively a higher proportions of plant species were found to be used for the treatments of respiratory diseases $(32.8 \%)$, followed by for the treatment of miscellaneous disease conditions such as swellings/tumors, toothache, headache, etc. (20.9\%), and gastrointestinal related complaints (18.4\%) (Fig. 2). It could be noted from the respondents' information that one species of plant can be used to treat different ailments or different 
species can be used in combination to treat a specific disease condition of human or animal diseases. Other studies from Africa and elsewhere $(13,15)$ recorded a similar trend of traditional medication. Mirutse (11) documented Meinit medicinal plants and found that $47 \%$ were used to treat gastro-intestinal complaints, 29\% skin-related diseases and $16 \%$ respiratory system problems. Although the ailments in both Meinit and the present community were similar, the frequency of disease conditions and use of medicinal plant species in the present study areas are slightly different.

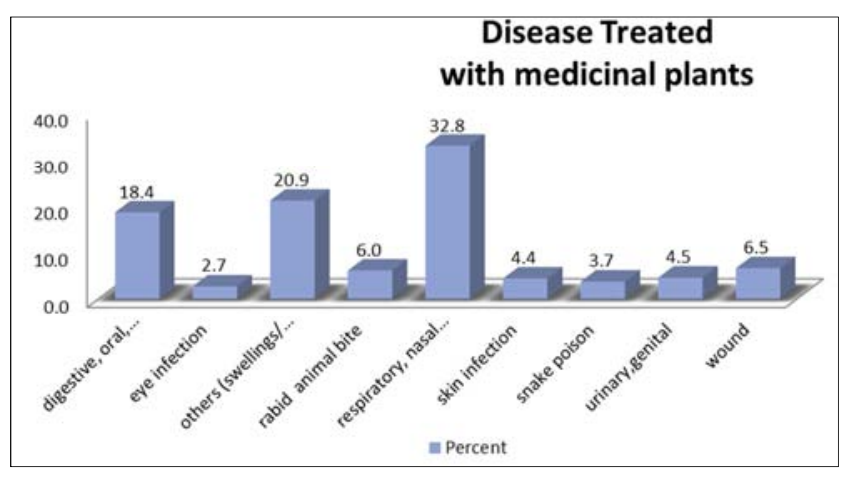

Figure 2. Diseases treated by plants.

\subsection{Methods of Preparation of Traditional Medicines}

According to the respondents the most frequent methods (95.7\%) of preparation of plant medicines in the studied communities were squashing/grinding of plant parts and extracting juicy ingredients, followed by $1.6 \%$ drying and grinding to make powder for direct application on infected body parts, $1.2 \%$ direct application on infected site and $0.6 \%$ decoction and fumigating each.

\subsection{Route of Administration}

People of the studied area, mostly administer traditional medicine orally. This route of administration accounted for $69.1 \%$, followed by dermal route of administration (12.7\%), nasal route $(6.5 \%)$ and the remaining administration routes such as smearing, infusion, vaginal and optical each accounted to less than $1 \%$ (Figure 3).

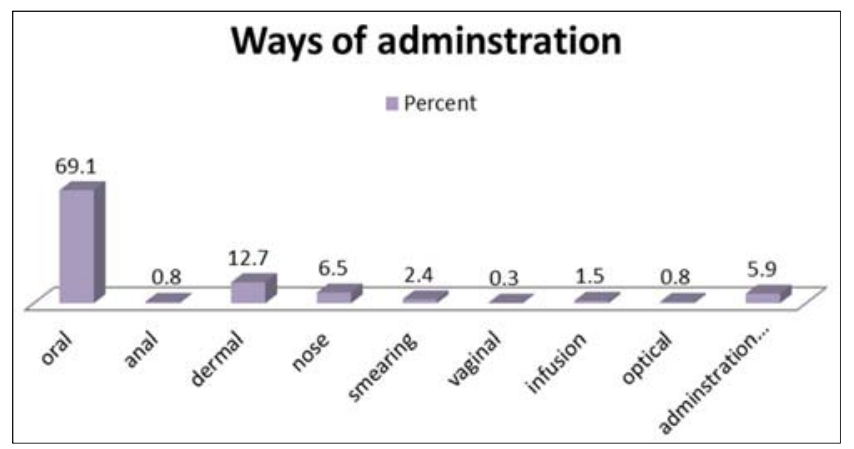

Figure 3. Ways of administration of traditional medicine.

\subsection{Most Preferred Medicinal Plants}

Of the total 146 (127 identified to the family and species level and 19 unidentified) in the study area Ocimum lamifolium 52 (9.45\%), Croton macrostachyus 26 (4.72\%) and Phytolacca dodecandra 22(4\%) were the most frequently preferred medicinal plants (Table 6).

Table 6. Preference ranking of medicinal plant in the study area.

\begin{tabular}{llll}
\hline Medicinalplantname & Frequency & Percentage & Rank \\
\hline Ocimum lamifolium Hochst. ex. & 52 & 9.45 & 1 \\
Benth & 26 & 4.72 & 2 \\
Croton macrostachyus Del. & 22 & 4 & 3 \\
Phytolacca dodecandraL' Herit & 20 & 3.63 & 4 \\
Ranunculus multifidus Forssk. & 19 & 3.45 & 5 \\
Ruta chalpensis L. & 13 & 2.36 & 6 \\
Vernonia spp & 12 & 2.18 & 7 \\
Clematis longicauda Steud. Ex A. & & 2.18 & 8 \\
Rich & 12 & 2.18 & 8 \\
Cynoglossum lancelotum Forssk. & 12 & 2 & 9 \\
Sature japaradoxa (Vatke)Engl. & 11 & 2 & 9 \\
Maesa lanceolata Forssk. & 11 & & \\
Rumex nepalensis Spreng. & & & \\
\hline
\end{tabular}

The respondents have indicated the different ways and means they determine the dosage of medicinal preparations used in the treatment of both human and animal diseases. Out of the total 136 medicinal plant preparations, $50.8 \%$ of them were taken by either as one fourth or half a cup, $15.7 \%$ are taken in one fourth or half a spoonful, $6 \%$ are taken in one fourth or half a glassful and in $0.3 \%$ dosage is undefined (Table 7). This result is also in line with the findings of Reta Regassa (15) which explain as local units for instance, half a cup, a full cup, were widely used to estimate and fix the amount of dosage.

Table 7. Dosages of medicinal preparations used.

\begin{tabular}{lll}
\hline Measurement & Frequency & Percent \\
\hline spoon, one fourth, half etc & 94 & 15.7 \\
drop, & 14 & 2.3 \\
In cups, one fourth, half & 304 & 50.8 \\
In glass, half, one fourth etc & 36 & 6.0 \\
Other units & 26 & 4.3 \\
No definite quantity & 101 & 16.9 \\
Total & 598 & 100.0 \\
\hline
\end{tabular}

\section{Conclusion}

Documentation and digitization of traditional medicine knowledge is the surest means of preservation. One of the major problems with traditional medicine knowledge is the oral nature of the knowledge. Hence documentation ensures preservation of this delicate knowledge and ensures wider dissemination. It will also result in codification of best practices which can be transmitted across communities in developing countries. Documentation and digitization of traditional medicine knowledge is an effective tool for defensive protection from biopiracy as well as expropriation without compensation by multi-national pharmaceutical companies. Documentation provides evidence that a particular medicinal knowledge has developed in a particular local community thus vesting the community with claim over such knowledge as well as right to share in any profit 
resulting from the commercialization of the knowledge (16). Documenting traditional knowledge associated with medicinal plants is also significant in the implementation of the third objective of CBD as well as in scientific research and development.

The large area covered by 2 districts, Decha, and Sheybench (Kaffa and BenchMaji respectively)was found to contain diverse medicinal plants and the associated traditional knowledge and practices. This is due to wide range of climatic and ecological variation as well as the presence of different ethnic community in the area. The altitude range varies from $1500-1900 \mathrm{~m}$. a. s. There is also relatively low interference by human activities. Although there is wealth of medicinal plants and traditional knowledge that has been applied in the treatment of human and animal health problems, the sustainability of these heritages has been challenged increasingly by human and environmental factors. According to the respondents the traditional medicinal practices has been discouraged by modern health care system due to fear of inappropriate dosage and safety issue. More over there has been spiritual cult that confuses medicinal property of the plants, so documentation of traditional medicinal practices is crucial to refine the traditional knowledge associated with medicinal plants.

Therefore in addition to documenting traditional medicinal plants and the associated knowledge, it is important to test the scientific validity of the herbal preparations to establish appropriate dosages and conduct clinical studies to ensure the safety of the traditional medicines if we are to benefit sustainably from these heritages.

\section{References}

[1] Fulvio, M. (2006). Western Science and Traditional Knowledge: Despite their variation, different forms of knowledge can learn from each other. EMBO Rep.7(5): 463466.

[2] Kackenzie Valley Environmental Impact Review Board (2005). Guide lines for incorporating traditional knowledge in environmental impact assessment. Pp. 3-35.

[3] Luke, E. M. and Wilson, M. (2012). Traditional knowledge and Plant Genetic Resources Guide. Lin. SAN Bio/ NEPAD Agence. Pp.70.
[4] Folke, C. (2004). Traditional knowledge in social-ecological systems. Ecology and Society, 9(3):7.

[5] Jane, A. (2005). Access and control of indigenous knowledge in libraries and archives: ownership and future use.The Mac Arthur Foundation, Columbia University, New York. Pp.1-36.

[6] Deborah, M. G. (2006). Traditional ecological knowledge, In: Ideas, the Arts and Science Review, 3(1).

[7] Huuter, K. B .and Jane, S. (2002). Soft ware tools for indigenous knowledge .Management file:// $p: w w w / p u b l i c / h t$ docs/I RM_project/software_paper/IKM_soft ware.htm.

[8] Milestad, R. and Hadatsch, S. (2003). Organic farming and social-ecological resilience: the alpine valley of Solktaler, Austria. Conservation Ecology 8(1):3.

[9] Mahalik, P. R and Rabindra, K. M. (2010). Documenting indigenous traditional knowledge in Odisha. Orrisa Review, May-June, Pp.99-103.

[10] Bekele, E. (2007). Study on actual situation of medicinal plants in Ethiopia, prepared for JAICA F(Japan Association for International Collaboration of Agriculture and Forestry), Pp. 73..

[11] Giday, M., Asfaw, Z. and Woldu, Z. (2009). Medicinal plants of the Meinit ethnic group of Ethiopia an ethnobotanical study. J. Ethnopharmacol.doi: 10. 1016/j.jep.2009.05.009.

[12] Hailemariam, T., Demissew, S. and Woldemariam.A (2009). An ethnobotanical study of medicinal plants used by local people in the low lands of Konta Special Woreda, southern nations, nationalities and peoples regional state, Ethiopia, Journal of Ethnobiology and Ethnomedicine, 5:26.

[13] Abate, G. (1989). Etse Debdabe (Ethiopian Traditional Medicine). Addis Ababa University, Addis Ababa (in Amharic).

[14] Maroyi, F. (2013). Traditional use of medicinal plants in south-central Zimbabwe: review and perspectives. Ethnobiology and Ethnomedicine, 9:31.

[15] Retaregasse (2013). Assessment of indigenous knowledge of medicinal plant practice and mode of service delivery in Hawassa city, southern Ethiopia. Journal of Medicinal Plants Research. 7(9), pp. 517-535.

[16] Emcee, C. LL. M, G. (2009). Digitization of intellectual property right and access to traditional medicine knowledge in developing countries-the Nigerian experience. A Research Paper Prepared for International Development Center (IDCR), Ottawa, Canada. 